\title{
Intensified glucose lowering in type 2 diabetes: don't throw the baby out with the bathwater
}

\author{
J. H. DeVries
}

Received: 10 October 2010 /Accepted: 9 November 2010 /Published online: 3 December 2010

(C) The Author(s) 2010. This article is published with open access at Springerlink.com

Keywords Cardiovascular disease - Glycaemic control Guidelines $\cdot$ Risk factors $\cdot$ Risk reduction - Type 2 diabetes

$\begin{array}{ll}\begin{array}{l}\text { Abbreviations } \\ \text { ACCORD }\end{array} & \begin{array}{l}\text { Action to Control Cardiovascular Risk in } \\ \text { Diabetes }\end{array} \\ \text { ADVANCE } & \begin{array}{l}\text { Action in Diabetes and Vascular Disease: } \\ \text { Preterax and Diamicron Modified Release } \\ \text { Controlled Evaluation }\end{array} \\ & \text { Number needed to treat } \\ \text { NNT } & \text { UK Prospective Diabetes Study } \\ \text { UKPDS } & \text { Veterans Affairs Diabetes Trial } \\ \text { VADT } & \end{array}$

To the Editor: In their Editorial, Yudkin, Richter and Gale argue that 'Hyperglycaemia is a substantially weaker risk factor for CVD than cholesterol or blood pressure, and glucose-lowering interventions are correspondingly less effective' [1]. They come to this conclusion on the basis of number needed to treat (NNT) derived from epidemiological studies, the UK Prospective Diabetes Study [2] and three recent megatrials (Action to Control Cardiovascular Risk in Diabetes [ACCORD] [3], Action in Diabetes and Vascular Disease: Preterax and Diamicron Modified Release Controlled Evaluation [ADVANCE] [4] and Veterans Affairs Diabetes Trial [VADT] [5]), which were subsequently meta-analysed. Of course, the results of any meta-analysis are dependent on the validity of the individual trials analysed. The external validity of ACCORD and VADT is

J. H. DeVries $(\bowtie)$

Academic Medical Center, Internal Medicine, P.O. Box 22660, Amsterdam 1100 DD, the Netherlands e-mail: j.h.devries@amc.uva.nl severely compromised with the recent decision of the European Medicines Agency to retract the market authorisation of rosiglitazone. In VADT, all patients in the intensively treated group were started on rosiglitazone by trial design. In ACCORD, 91.2\% of patients were on rosiglitazone in the intensively treated group. It seems impossible to draw any conclusion on possible cardiovascular benefits of glucose lowering if such glucose lowering was attained using a drug which has now been concluded to increase the risk of myocardial infarction by its very nature. So we are left with UKPDS and ADVANCE as the relevant studies. The key differentiators between these two studies are duration of disease at enrolment and the treatment targets in the intensively and conventionally treated groups. In UKPDS, patients were randomised soon after the diagnosis of type 2 diabetes was made, and ADVANCE enrolled patients with a diabetes duration of 8 years. Using the UKPDS follow-up data [6], Yudkin et al. calculated the NNT for 10 years to prevent one myocardial infarction or stroke to be 29.4 [1]. This number relates to the sulfonylurea-insulin group. In the metformin group, the corresponding NNT is 14. Moreover, the 10 year NNT to prevent one death was 29 in the sulfonylurea-insulin and 14 in the metformin group. I think most diabetologists would agree that patients with newly diagnosed diabetes are entitled to treatment aiming to achieve an $\mathrm{HbA}_{1 \mathrm{c}}$ value of $<7.0 \%$ for at least 10 years. There is no reason to believe that the UKPDS results would have been different if the trial had been of longer duration, so it seems reasonable to keep this as the $\mathrm{HbA}_{1 \mathrm{c}}$ target. After the first 10 years of diabetes, ADVANCE becomes a relevant study. This study showed only minimal beneficial effects of intensive treatment of glucose as compared with conventional treatment, but it should be noted that mean $\mathrm{HbA}_{1 \mathrm{c}}$ in the conventionally 
treated group was maintained at $7.3 \%$ throughout the trial. There is no trial evidence to indicate that $\mathrm{HbA}_{1 \mathrm{c}}$ levels above this are safe. Therefore, treatment guidelines will probably continue to advise a target $\mathrm{HbA}_{1 \mathrm{c}}$ of $7.0 \%$ for people with diabetes, with the possibility of a slightly higher target of $7.3 \%$ after a diabetes duration of $8-10$ years. Of course, considerations relating to hypoglycaemia, weight gain, diminished life-expectancy or adherence may well justify higher targets in selected individuals.

Duality of interest The author declares that there is no duality of interest associated with this manuscript.

Open Access This article is distributed under the terms of the Creative Commons Attribution Noncommercial License which permits any noncommercial use, distribution, and reproduction in any medium, provided the original author(s) and source are credited.

\section{References}

1. Yudkin JS, Richter B, Gale EA (2010) Intensified glucose lowering in type 2 diabetes: time for a reappraisal. Diabetologia 53:20792085

2. UK Prospective Diabetes Study (UKPDS) Group (1998) Intensive blood-glucose control with sulphonylureas or insulin compared with conventional treatment and risk of complications in patients with type 2 diabetes (UKPDS 33). Lancet 352:837-853

3. The Action to Control Cardiovascular Risk in Diabetes Study Group (2008) Effects of intensive glucose lowering in type 2 diabetes. N Engl J Med 358:2545-2559

4. The ADVANCE Collaborative Group (2008) Intensive blood glucose control and vascular outcomes in patients with type 2 diabetes. N Engl J Med 358:2560-2572

5. Duckworth W, Abraira C, VADT Investigators et al (2009) Glucose control and vascular complications in veterans with type 2 diabetes. N Engl J Med 360:129-139

6. Holman RR, Paul SK, Bethel MA, Matthews DR, Neil HA (2008) 10 -year follow-up of intensive glucose control in type 2 diabetes. N Engl J Med 359:1577-1589 